\title{
Infrared thermography for a quick construction progress monitoring approach in concrete structures
}

\author{
Mehdi Pazhoohesh ${ }^{1}\left[\right.$ ] Cheng Zhang ${ }^{2} \cdot$ Amin Hammad $^{3} \cdot$ Zahra Taromi $^{4} \cdot$ Armin Razmjoo $^{5}$
}

Received: 15 June 2021 / Accepted: 20 September 2021/Published online: 14 October 2021

(c) The Author(s), under exclusive licence to Springer Nature Switzerland AG 2021

\begin{abstract}
Construction progress monitoring ensures the construction project is consistent with the schedule and enables the detection of any deviations in the geometry and/or any variation in the schedule. The traditional progress monitoring requires specialized personnel to walk around on the construction site to manually collect data and verify the progress of activities, which is time consuming, costly and/or error prone. Image-based technology is effective for recording on-site data geospatially and chronologically. It has gained increasing attention in the construction field for progress monitoring, work space analysis and quality assurance. However, a notable downside of image processing is the light condition, particularly for noisy environments such as construction sites. Poor or undesirable ambient light conditions produce low quality images that significantly affect the accuracy of data extracted from related images and lead to a high level of errors. This paper presents an innovative approach based on thermal image analysis to overcome problems related to the image quality. Thirty preliminary tests and three case studies have been implemented to show the feasibility of the method. A range of improvement between 8 to $48 \%$ has been attained that confirms the great potential of thermal images to overcome the limitation of image-based approaches.
\end{abstract}

Keywords Infrared camera $\cdot$ Construction progress monitoring $\cdot$ Image-based $\cdot$ BIM $\cdot$ Thermal image

\section{Introduction}

These days, due to importance of buildings in cities, the use of new management methods has become more common than before $[1,2]$. Construction progress monitoring has been repeatedly reported as an essential factor for the success of large-scale construction projects [3-6]. Traditionally, specialized personnel walk around on the construction site to collect data manually and verify the progress of activities.

Mehdi Pazhoohesh

mehdi.pazhoohesh@dmu.ac.uk

1 School of Engineering and Sustainable Development, De Montfort University, Leicester, UK

2 Department of Civil Engineering, Xi' an Jiaotong-Liverpool University, Suzhou, China

3 Concordia Institute for Information Systems Engineering, Concordia University, Montreal, Canada

4 Department of Computer Engineering, Shahid Beheshti University, Tehran, Iran

5 Escolla Técnica Superior d'Enginyeria Industrial de Barcelona (ETSEIB), Universitat Politécnica de Catalunya (UPC), 08028 Barcelona, Spain
This method requires widespread data extraction from drawings, schedules and budget information, which is a time consuming process in addition to the quality issues of the resulting reports. Mistakes and inaccuracies in these reports are inevitable due to the manual work. Therefore, project participants are increasingly relying on using information technology to collect data and update project progress. The recently developed automated construction progress monitoring systems can significantly improve the quality and efficiency of the construction management. The comparison of current state (as-built) and target state (as-planned) information enables the detection of any deviations in the geometry and/or any variation in the schedule; therefore, early warning indicators of potential delays can be delivered to the project managers.

Photogrammetry is an image-based measurement that can be used for construction progress monitoring. Meanwhile, there has been remarkable development in computer vision, considered as an essential part of image-based automatic monitoring systems. Affordable imaging devices, less computational time, simplicity in operation, and the extraction of information from image data for nuanced site representation can be all mentioned as the significant advantages of 
image-based monitoring systems [7, 8]. Despite the advantages of image-based methods, several disadvantages make it a challenging task for automated monitoring systems, e.g., dependency on the image quality and resolution. Generally, image noise, static and dynamic occlusions, shadows, bad ambient light conditions and low-level detection of the object edges significantly reduce the precision of image analysis and make it difficult to identify the actual objects [6]. Hence, developing a method that overcomes such issues may lead to significant improvement of image-based monitoring approach.

On the other hand, Building Information Modelling (BIM) has emerged as a project management tool to ameliorate the inherent limitations associated with 3D ComputerAided Design (CAD) models. BIM is a shared knowledge resource which can reduce the need for re-gathering or reformatting information. 4D BIM model is the combination of 3D geometry and the schedule of construction activities, that provides the expected on-site situation at specific time during construction $[9,10]$. Therefore, it can be used as an as-planned model to effectively identify any schedule and/ or budget variances by comparing with the as-built model. This can lead to reducing the time and increasing the accuracy of transmitted data, and thus reducing the costs of the project [11-13]. However, the as-built BIM model is often not updated frequently throughout the construction phase.

The integration of BIM and image-based monitoring technique could lead to a powerful progress monitoring system. Vision based systems for tracking progress has become a new trend in the current research $[6,14-18]$. A three step process is generally employed by these systems: (i) Capturing time lapsed photographs usually from a fixed location; (ii) Importing the images to 3D CAD or BIM models taking into consideration the coordinates and camera poses; and (iii) A comparison is made between 2D site images and the as planned model. Each BIM component is distinguished through the image analysis and the corresponding location and the scheduled time are compared with the expected developing model [14].

In a study conducted by Gerrish et al. (2015), daily construction photographs and 4D BIM model are used to detect progress deviations. A general assumption is that construction workflow for any given activity is unknown and level of detail will be described in the schedule explicitly (such as concreting needs forms, rebar, pouring and striping). Secondly, operation details are not considered and the observation is supposed to be on the day when the element is to be placed (e.g. forming stage of columns is not considered). However, formulation accounts for operational details. On the other hand, adding to the problems of the image-based monitoring systems, linking as-planned models with captured photos for the monitoring process is also a challenge. Firstly, it is difficult to match the location of photos taken with the sketch (checkpoints) since most of the pictures are taken from different locations and angles. According to Golparvar-Fard et al. [19], lots of effort should be put on reconstructing as-built point-cloud models from unordered daily photos and registering point-cloud models to generate the whole as-built model. Secondly, the un-calibrated images with widely uncontrolled and unpredictable light conditions significantly reduce the accuracy of image processing [20]. Finally, the visibility and occlusions are known as the principal reasons to cause low quality images [20].

The present paper proposes a method by using infrared cameras, that can detect the surface temperature of the target objects and adds extra information about the edges of the concrete objects; therefore, the disadvantages of traditional image-based method can be overcome. Infrared cameras have been previously used for adding thermal information of the existing buildings but their utility in construction activities related noise reduction has seldom been studied. In the proposed approach a location-based system has been used to record the locations of the thermal cameras while taking photos to obtain corresponding images from the BIM model so as to enable the analysis based on superimposing the optical image, the thermal image and the image from the 3D model. Finally, an automatic updating of the BIM model with as-built information can be accomplished. The major focus of the present paper is put on concrete structural components since concrete has significant temperature changes during the curing process, which enables easy detection of objects in the thermal pictures.

\section{Research background and objectives}

There are two major systems being used to model the actual state of construction progress: laser-scanning-based and image-based. Both systems conduct the process of collecting data from the site, identifying existing components, and generating 3D models to be integrated into existing models.

In a laser scanning-based system a laser range scanner is utilized to collect point clouds and merge them into a 3D model in CAD/BIM [21]. Recent applications of this method can be construction quality control [22], conditions assessment [23], health monitoring [24] and component tracking [3, 25]. For instance, [26] have introduced a top-down technique utilizing point clouds of RC bridges to identify bridge components. Yang et al. [27], have proposed a laser scanning based approach to extract the geometry information of complex steel structure components and automatically generate the as-built BIM model. For progress monitoring purposes, Bosche et al. [4], for example, have presented a semi-automated registration method for aligning the as-built and as-planned models, in which the point cloud is generated based on manually selecting 
at least three pairs of corresponding points in the two laser sets. Laser scanning is also integrated with other data such as schedules. Turkan et al. [28] have proposed a progress tracking system that fuses 3D laser scans with 4D models to automate construction progress monitoring. Their system is tested for a concrete building construction project and the results indicate the importance of the planning of scan. However, temporary occlusions lead to low level object identification. Pučko et al. [29] introduced a continuous point cloud acquisition of all changes during the construction process by fitting workers' helmets with low precision 3D scanning devices. However, such techniques require precise indoor and outdoor localization systems.

Despite the accuracy of laser-scanning-based techniques, costs, resolutions, the mixed-pixel issues, regular sensor calibrations and slow warm-up time are noted as the main drawbacks of this method $[3,30]$.

Image-based systems are considered as an affordable method for many construction companies to collect data. Numerous studies have been conducted to utilize and improve the image data for construction project monitoring and management purposes. Neto et al. [31] have proposed a colour-edge-detector algorithm to identify the construction components, in which a predefined library based on the RGB ranges for different materials is created. Zou and Kim [32] have developed a method based on HSV (hue, saturation, and value) and colour to compute the idle time of hydraulic excavators automatically. Golparvar-Fard et al. [14] have proposed an image-based approach to estimate project status information using daily photographs captured from a construction site. In their research, time-lapsed images have been created with all building components to specify whether or not specific areas have expected appearances and the construction progress can therefore be monitored.

Zhu \& Brilakis [33] discussed an automated concrete column detection approach using line-segment pairs. In this study, edge detection and Hough transform have been utilized to recognize the reinforced concrete (RC) columns in an image. They have reported 38 out of 51 successful columns detection over 20 captured images.

Braun et al. [34] have introduced photogrammetric point clouds to facilitate the as-planned versus as-built comparison. In that method, a dense point cloud is reconstructed from the images, which is compared to an existing 4D building model. Asadi et al. [35] proposed an approach by performing an augmented monocular simultaneous localization and mapping (SLAM) to detect and match between a series of image frames and their corresponding BIM views. They reported an increase error rate on the estimated components with curved shape as their method has developed based on the detecting straight edges on images. Hence, this method could lead to further errors in a noisy construction site.
However, due to the numerous obstructions found on a construction site, only a minority of building elements are detected successfully. Zhang et al. [6] and Lukins and Trucco [16] have presented a similar automated method with a different recognition stage. In their method, a comparison is made between pre-calibrated images and previous photos. Specific areas of interest are analysed by focusing on pixel changes to detect any differences from past photos. The time-lapsed images method has the most automation reported so far. However, it has many limitations: (1) The fixed camera has limited the analysis to only the closest structural frame to the camera,(2) Lighting conditions and shadow issues significantly affect the image processing; (3) Dynamic occlusions make it difficult to analyse the components; and (4) Static occlusion may result in false detection [14].

Infrared thermography is the technique of measuring infrared radiation emitted by bodies, proportionally dependent on their superficial temperature [36]. The use of this technique has been usually limited to three types of applications in the construction related research. The first includes obtaining the thermographs of an existing building for analysing the heating or cooling energy requirement of the building envelop taking into account the local climate $[37,38]$. The second relates to the real-time defect detection (air infiltrations, thermal bridges and moisture areas) in retrofitting existing building system in terms of energy efficiency for heating or cooling loads [39, 40]. The third use is associated with material detection of the existing buildings [41]. However, very few studies have indicated its utility in the application of photogrammetric principles for the measurement of geometry directly from thermographs $[42,43]$, or from a combination of visible and thermographic images looking for an improvement in the geometric resolution [44]. Lagüela [45] purely investigated the extent of thermographic images to represent the as-built geometry and successfully extracted height, width and openings of the structure.

To overcome the limitations mentioned in the literature review, a new method based on infrared-cameras is proposed in the present research. The objectives of the present paper are as follows: (i) To propose an innovative method in the image-based progress monitoring techniques so as to mitigate the errors related to noises, light conditions and image resolutions; (ii) To investigate the feasibility of identifying concrete structural components using the proposed method; and (iii) To automatically identify newly constructed elements and update in BIM model for progress monitoring purposes.

\section{Feasibility analysis and experimental measurement}

Infrared-camera, which is also known as IR-camera, is acting as a non-contact sensor absorbing the heat energy from surfaces of objects and giving an illustration in the form of 
thermal images. This device allows users not only to measure temperature, but also to detect and evaluate any heatrelated parameters such as humidity. Due to the existence of blackbody radiation, objects produce electromagnetic wave radiation to the external environment ( [46]. Wavelength that is between $2 \sim 1000$ micron is called thermal infrared. Thermal infrared images are based on thermal infrared sensitive Charge-Coupled Device (CCD) imaging of objects. These images reflect the temperature field of the object surface. Different colours will be presented based on the surface temperature of the objects.

Concrete is the most widely used material in construction projects. As the key constituents of concrete, cement releases heat when in contact with water, which is known as cement hydration. Three stages are involved in the hydration process. The first stage is a dormant period, where at the initial moment of reaction, water contacts cement particles, and the heat starts to be released. However, due to the existence of gypsum in cement, a thin film is produced and covers around cement particles. The reaction rate decreases due to the filming and heat release rate decreases correspondingly. The second stage is phase-boundary reaction stage, which is characterized by the highest heat release rate. Cement particles are continuously produced by reaction and the production rate increases quickly. Therefore, the heat produced by the hydration is the highest among the three stages. The third stage is diffusion control stage, where the cement particles are incessantly accumulated from previous stages and the reaction rate decreases; therefore, the heat released decreases gradually because the hydration is complete.

Based on the significant temperature changes during the hydration process of concrete, IR-camera is used to take thermal pictures of the concrete components on construction sites so as to investigate the feasibility of using the proposed method. Figure 1 shows the optical and thermal images taken by using an IR-Camera. The relative environmental temperature and humidity are $26.5^{\circ} \mathrm{C}$ and $44 \%$, respectively. The elements shown in the pictures are concrete beams precast manually. Beams in Zone 1 were casted 7 days prior to the photo being taken, while beams in zone 2 were casted 5 days prior to the photo being taken. The beams in zone 3 were casted in the morning and beams in zone 4 were casted $10 \mathrm{~min}$ before the photo being taken. The beams in Zone 4 can be regarded as fresh concrete. It is obvious from the thermal image that temperatures of these beams were different based on the colours and the shape of the beams can be easily identified by colours. In general, without considering the weather conditions, the surface temperatures of fresh and short-term concrete are higher than that of more aged concrete due to the hydration reaction. The surface temperature of the 7-day concrete is similar to that of the surrounding environment. Heat is absorbed by water evaporation so that the surface temperature of 5 days concrete is lower than that of fresh concrete. According to temperature differences and varied colour shown in the thermal images, the casting sequence of the beams can be estimated.

Further analysis has been done to evaluate the feasibility of using IR-camera for construction progress monitoring. Images of a selected concrete beam were taken for 6 consecutive days with time intervals of $0 \mathrm{~min}, 30 \mathrm{~min}, 60 \mathrm{~min}$, $120 \mathrm{~min}$ and $240 \mathrm{~min}$ for each day. Images were taken at 9:00 AM, 9:30 AM, 10 AM, 11 AM and 1 PM. Environmental temperature and humidity were recorded by using a thermometer at the moment when the thermal images were captured and the surface temperatures of concretes are extracted from thermal images. Figure 2 shows the temperature variation tendency of concrete along time. The relationship between environmental temperature and concrete surface also can be observed from these figures.

For fresh concrete, the maximum environmental and element temperatures are $34^{\circ} \mathrm{C}$ and $31^{\circ} \mathrm{C}$, respectively, as shown in Fig. 2(a). Environmental temperature is a bit higher than concrete temperature for fresh concrete. The reason can be that IR-Camera only measures the surface temperature of concrete, where water evaporation on the surface of concrete absorbs a large amount of heat. This process results in the lower surface temperature of concrete compared with environmental temperature. Water is a significant reactant
Fig. 1 Images of concrete beams

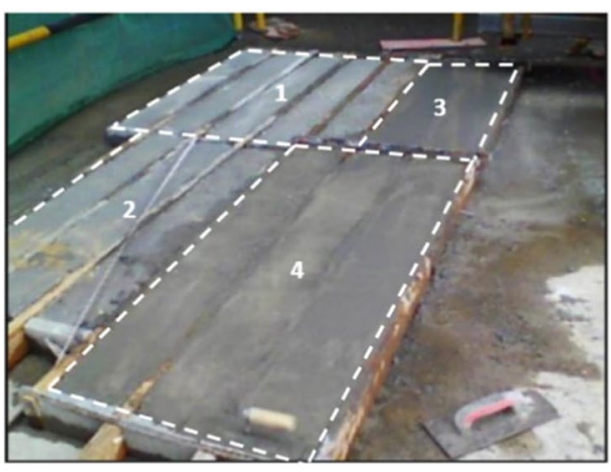

(a) Optical Image

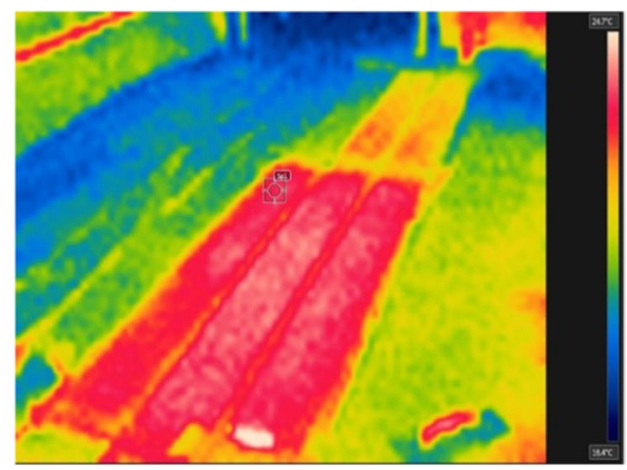

(b) Thermal Image 


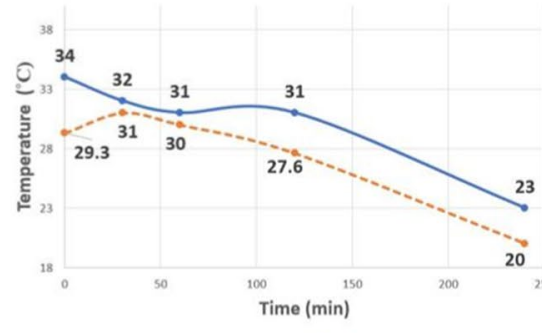

$\rightarrow$ Environment Temperature -.-. Concrete temperature

(a) Fresh Concrete (Day 1)

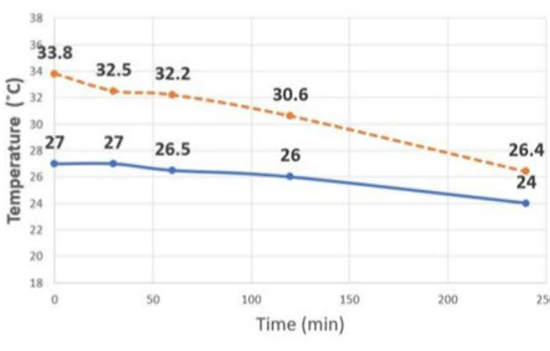

(d) Three-day old concrete (Day 4)

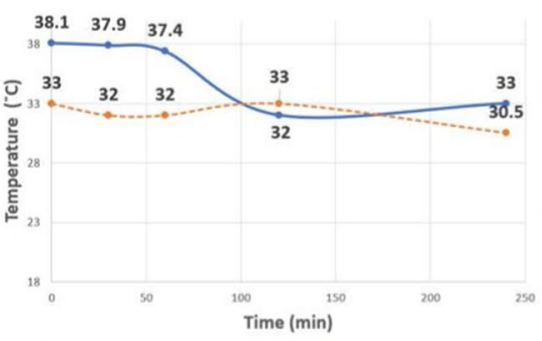

(b) One-day old concrete (Day 2)

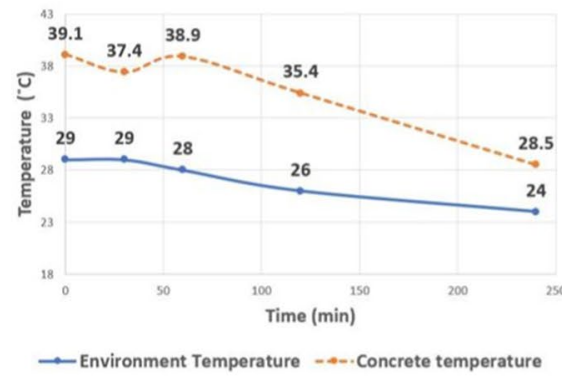

(e) Four-day old concrete (Day 5)

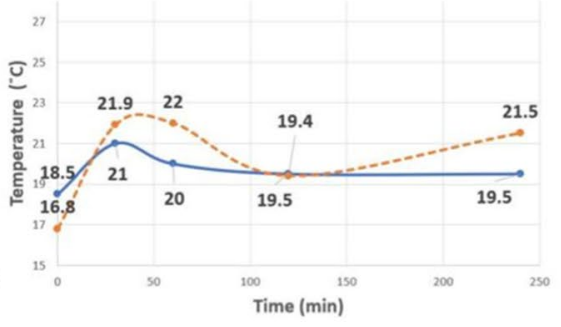

(c) Two-day old concrete (Day 3)

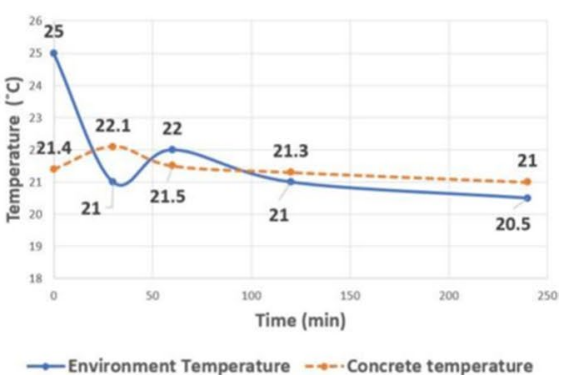

(f) Five-day old concrete (Day 6)

Fig. 2 Temperature variation of concrete and environment for six consecutive days

for cement hydration. Water evaporation restrains hydration reaction and thus decreases the amount of heat generation from hydration reaction.

As shown in Fig. 2(b), surface temperature of one-day concrete is higher than environmental temperature because the water has been evaporated after one day curing. Cement hydration continuously proceeds and heat is produced, therefore, the surface temperature of concrete is higher than environmental temperature. In addition, solar radiation also influences the surface temperature of concrete. The longer time of solar radiation, the higher surface temperature of the concrete compared with environmental temperature. When solar radiation is screened, the surface temperature of concrete will decrease.

Surface temperature variations of two, three, four and five days concrete are depicted in Figs. 2(c), (d), (e) and (f), respectively, showing that the surface temperature mostly remains above the environmental temperature, which supports the hypothesis that the temperature differences can be captured in the thermal image obviously. In some cases, as shown in Figs. 2(c) and (f), the temperature differences between the surface and environment are small due to the rainfall that occurred the day before. The evaporation process of water particles covering the surface of the concrete absorbed the heat, which led to the surface temperature decrease and close to the environmental temperature.

Figure 3 presents the variation of temperature differences between concrete surface and environment within the 6 consecutive days. The positive temperature variation increases continuously in the six days because of the heat generated continuously from the hydration reaction. Two peaks occurred on day two and day five with two sags appeared on day three and day six, which can be explained by the rainfall that occurred the day before.

The important finding from Figs. 2 and 3 is that surface temperature of concrete is significantly higher than the environment, especially in sunny days. While in rainy days, the difference is not so obvious.

To further investigate the feasibility of using thermal images, more pictures were taken on site in complex situations for structures under construction. Figures 4 and 5 illustrate the temperatures on the surface of concrete columns, stairs and scaffoldings. The areas with different

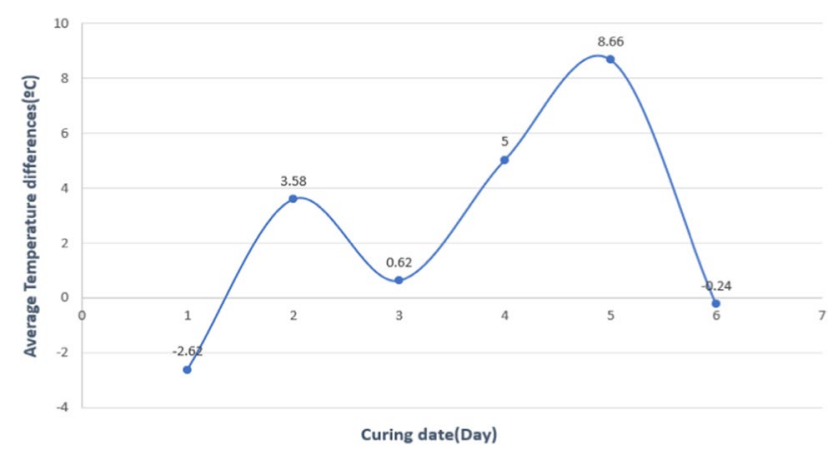

Fig. 3 Temperature differences of concrete and environment within 6 consecutive days 
temperatures can be identified clearly; even concrete components inside a formwork are detectable, as shown in Fig. 4.

Besides temperature, humidity is another parameter which should be taken into account since the temperature differences are not so obvious in rainy days. Using the Humidity filter available in the IR-camera, images taken show extra information besides the temperature. As shown in Fig. 6, zones with different humidity can be identified in different colours, which can be used as supplementary information to identify different elements on construction site.
As mentioned in the introduction section, lighting conditions are known as a big challenge in photometric image processing. To show how good that the thermal-imagesbased method can solve such problems, pictures were taken under a poor lighting condition, as shown in Fig. 7. It is nearly impossible to detect columns from the optical pictures (Figs. 7(a) and (c)). However, in the thermal images, they are easily detected, as shown in Figs. 7(b) and (d).

In some cases, due to the high congestion of scaffoldings or other occlusions, it is very difficult to identify the existence of elements from the images taken. Thermal
Fig. 4 Different temperature areas on the surface of concrete columns and stairs

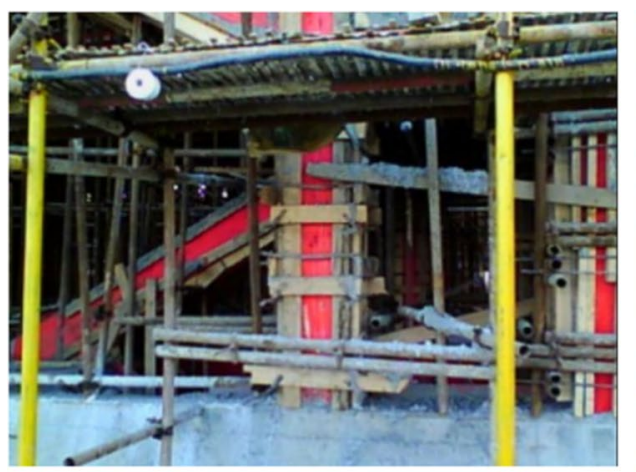

(a) Optical image

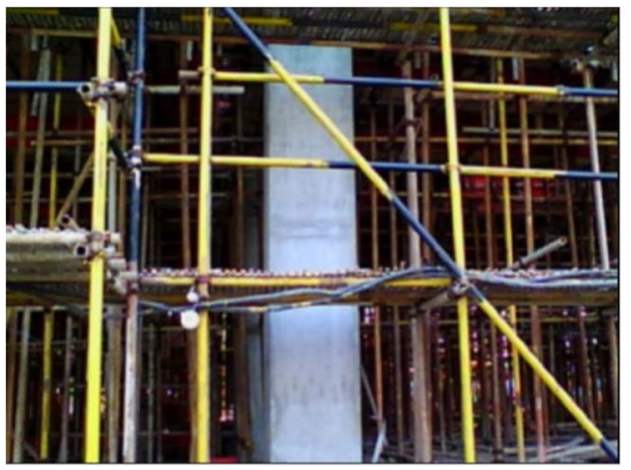

(a) Optical image

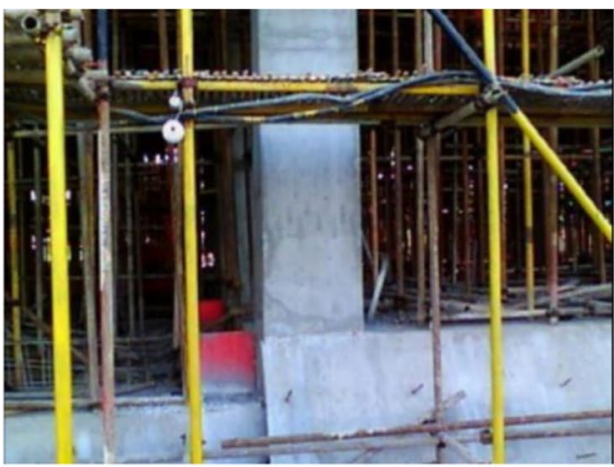

(a) Optical image

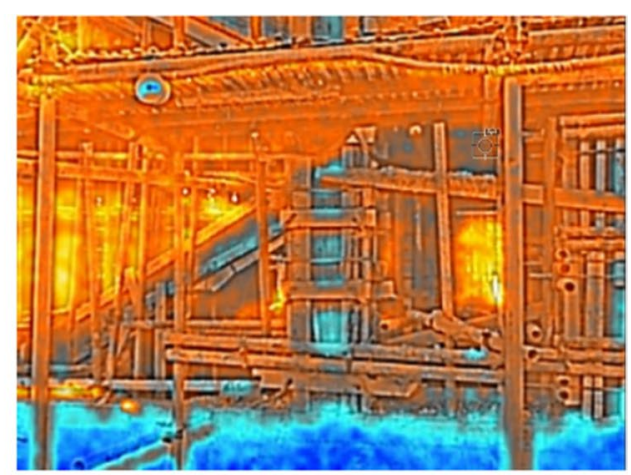

(b) Thermal Image

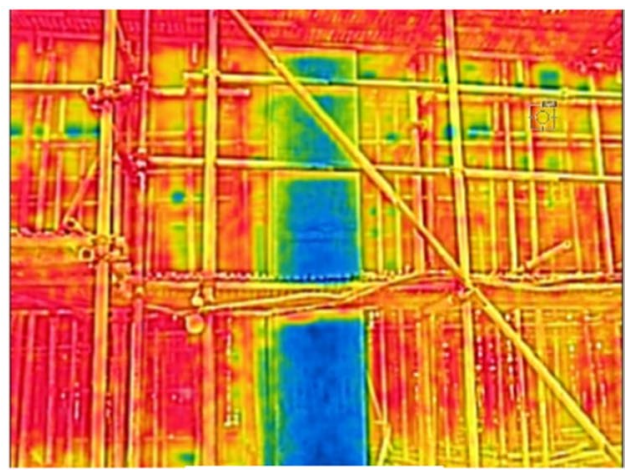

(b) Thermal Image

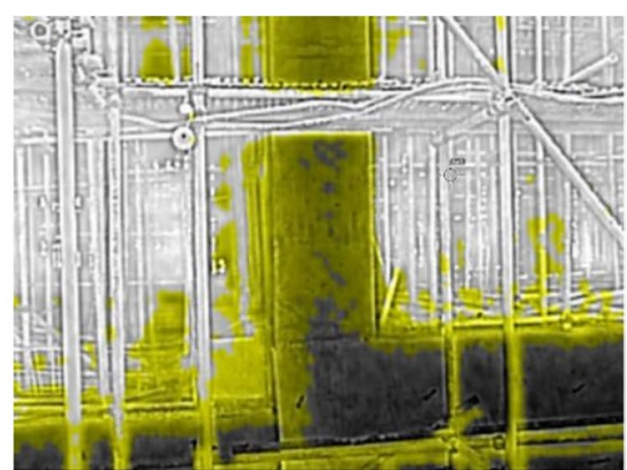

(b) Thermal Image with humidity filter
Fig. 6 Different humidity areas on the surface of concrete columns
Fig. 5 Different temperature columns 
Fig. 7 Identify areas from poor lighting condition image

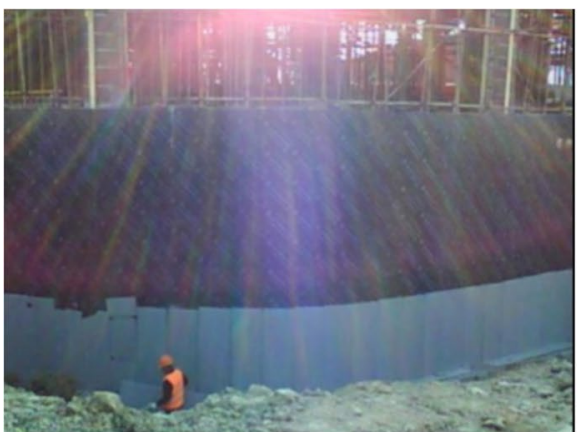

(a) Optical image with poor lighting condition

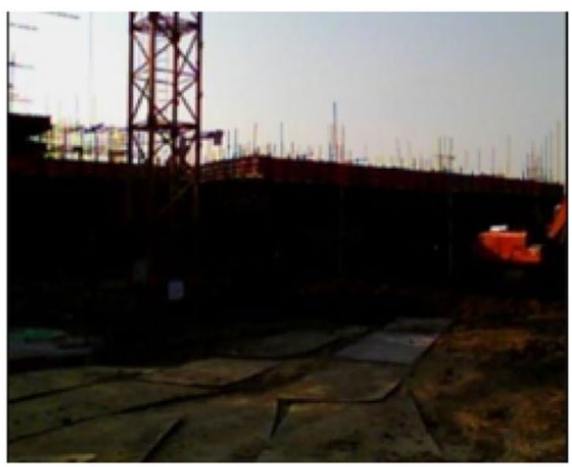

(c) Optical image with poor lighting condition

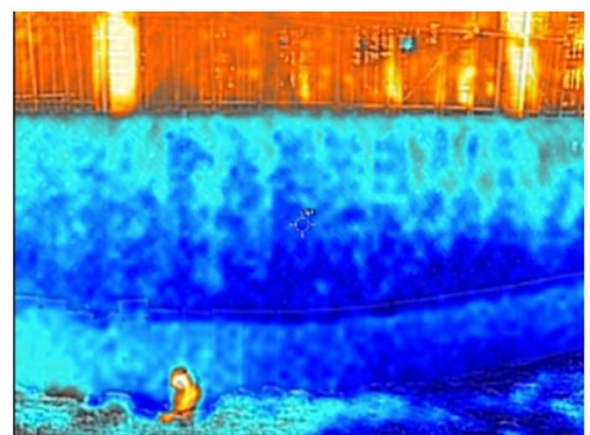

(b) Thermal image with poor lighting condition

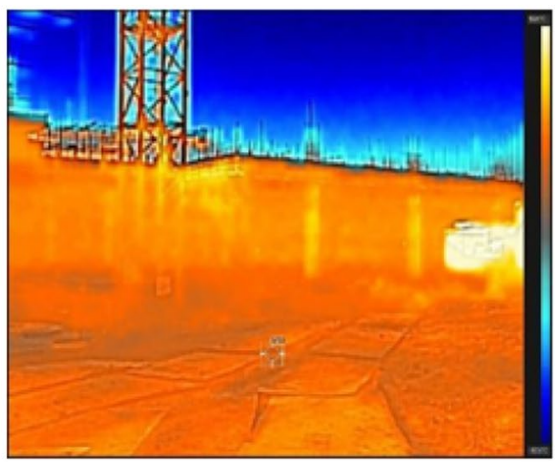

(d) Thermal image with poor lighting condition images can be really useful in such cases. A messy construction environment is shown in Fig. 8(a) with a thermal image shown in (b), which shows how significant the thermal images can be used for identifying the existence of elements in such a noisy environment.

To sum up, based on the feasibility analysis and experimental measurements, it is applicable to identify newly built concrete components on construction site based on thermal images taken by IR-Camera and develop an automated progress monitoring system. Hence, the proposed methodology is explained in the next section.

\section{Methodology}

The kernel point of this research is to take pictures of the construction site at designated locations, identify elements with different construction stages, and update the 4D BIM model. The process is based on the following assumptions: (1) The 3D BIM model and the construction schedule are available; (2) The structure is composed of reinforced concrete components; and (3) The location and orientation of the IR-camera can be tracked in real time. As shown in Fig. 9, the overall procedure for thermal-image-based automated progress monitoring is divided into four major
Fig. 8 Identify objects from a noisy environment

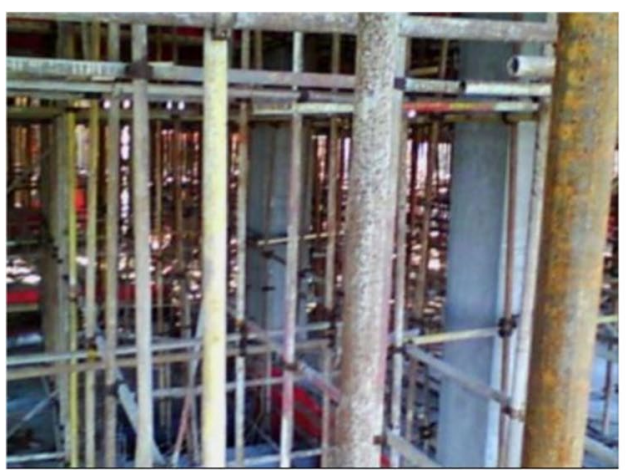

(a) Optical image from a noisy environment

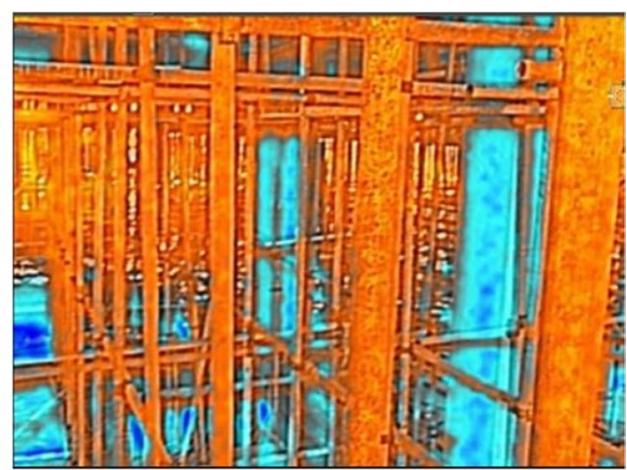

(b) Thermal Image from a noisy environment 
steps, which are: 4D BIM acquisition, onsite data collection, image processing, and model updating.

To automate this process, a plug-in is developed to indicate ideal camera locations for daily construction photographs and extract as planned camera-view images from the 4D model and update the BIM model according to the confirmation obtained from the image processing step. First, automatic progress monitoring plug-in is run on the BIM model, this plug-in will check the schedule and suggest ideal camera-location for image capturing from the site with respect to the current date, then daily photos will be taken from the construction site as per the suggestions, as shown in Fig. 9(a). This plug-in will also extract the expected progress images from the 4D BIM model at the location and orientation of the camera when capturing the pictures (Fig. 9(b)). A wireless sensor network is used to confirm the location of the camera on site. The purpose of the image processing step is to identify whether the scheduled components have been constructed or not. By applying a colour-based filter on the thermal images, environment noises such as occlusions can be removed. The edge detection and superimpose method are utilized to remove further noises. Next, raster cell method is applied on the output to confirm the presence of newly built components (Fig. 9(c)). More details for image processing are provided in Subsection 4.2. Finally, the confirmation obtained through the image processing dictates the element wise updating of the 4D model and schedule. (Fig. 9 part (d)).

\section{Onsite data collection}

In the proposed method, it is assumed that the construction schedule and 3D BIM model are available. The ideal location and orientation of the camera is suggested considering the effectiveness of capturing appropriate progress details. A plug-in is developed to retrieve the coordinates of the target components in the model and create a bounding box for that area, then identify the four corners as suggested locations to put the camera. Preliminary camera-view images are obtained from those locations to get a better understanding and select one or more locations to be used on site. A location system based on ZigBee wireless sensor network is used in this research to capture the location of the IR-Camera while capturing images on site. The network contains two types of nodes, reference and mobile nodes. Reference nodes are placed in locations with the known $\mathrm{X}$ and $\mathrm{Y}$ positions in a local coordinate system. The mobile node will collect data from reference nodes and calculate the position and send data to the server. ZigBee cc 2430 has been used as the reference node and ZigBee cc2431 has been considered as the mobile node. In our previous research, we introduced an enhanced indoor location system based on wireless sensor

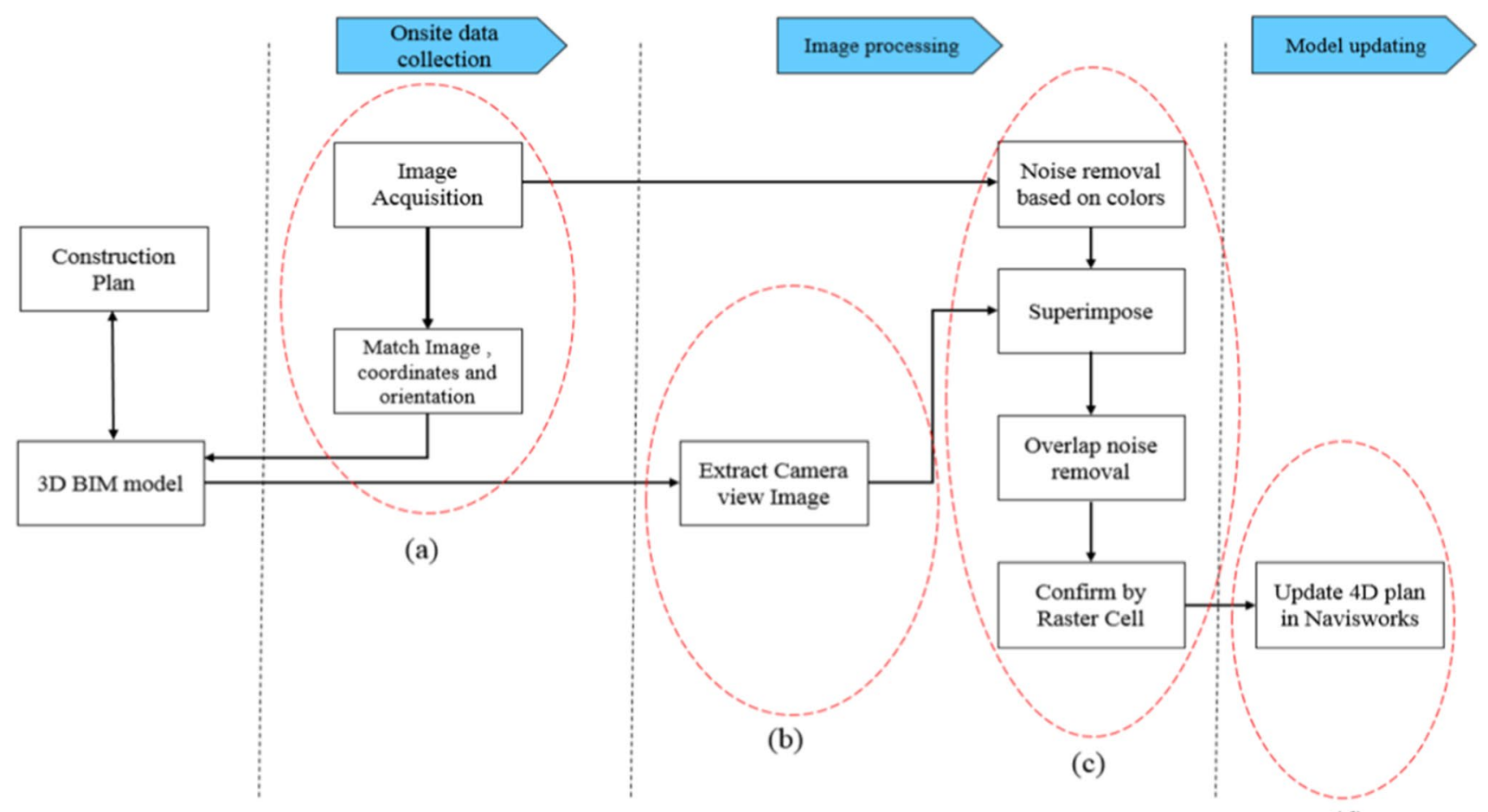

(d)

Fig. 9 Thermal image-based automated progress monitoring procedure 
networks [47, 48]. A principal component analysis (PCA) approach was used to smooth the unwanted signals in a noisy environment, which leads to a more accurate positioning estimation. By utilizing the same methodology, X and Y coordinates are recorded for the IR-camera when pictures are taken. The orientation data are manually recorded while taking each image on site, and will be used together with the coordinates to extract the corresponding 3D camera-view image from the BIM model. Based on the image captured, three types of images need to be processed for progress monitoring: optical, thermal and camera-view images. Optical and thermal images are taken simultaneously from the construction site by using IR-Cameras. Camera-view images are extracted from the 4D BIM model based on the location and orientation of the camera.

\section{Image processing}

As mentioned in Section 3, the difference of surface temperature between elements (e.g., concrete elements and scaffoldings) leads to different colours in thermal images. These differences are considered as a valuable point to remove useless objects from thermal images. However, some objects may have the same temperature as concrete elements. Hence, camera-view image and superimpose method is used to recognize the area of interests, as shown in the left-hand side part of Fig. 10. The occlusions are removed by applying a colour-based filter on the thermal image for removing useless areas. Afterwards, the edges of components in the camera view image are identified. In addition, superimpose is applied on both images to recognize the areas of interest. Non-overlap areas are removed from the superimposed image and called final noise removal filter. Next, raster cell method has been utilized to confirm the object's existence, which is shown in Fig. 11.

At the same time, the same image processing method is applied to the optical image, as shown in the right-hand side part of Fig. 10, and a grayscale image is generated to detect the edges of the components. The non-overlap areas are removed from the superimposed image based on optical
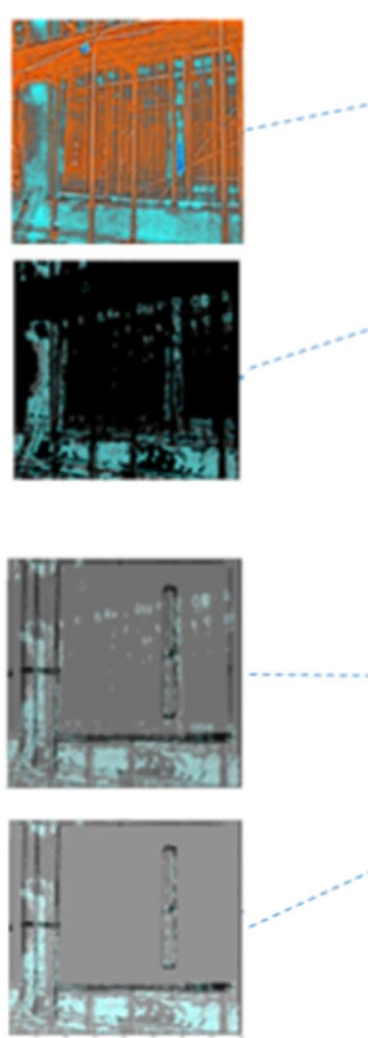

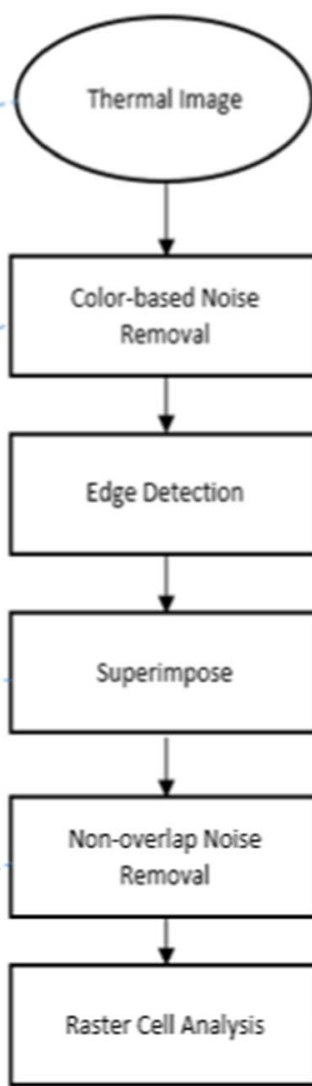

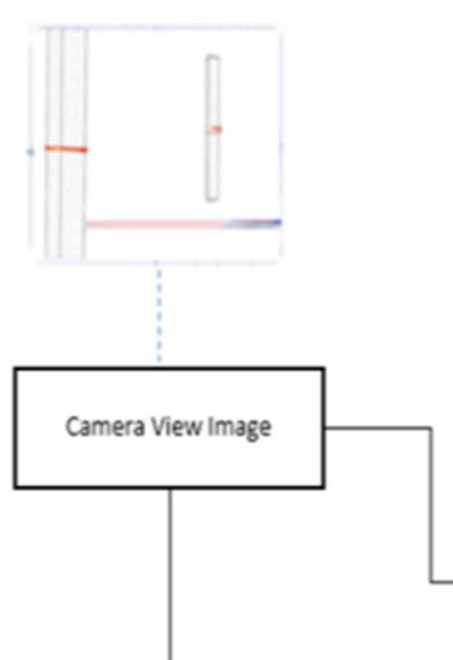
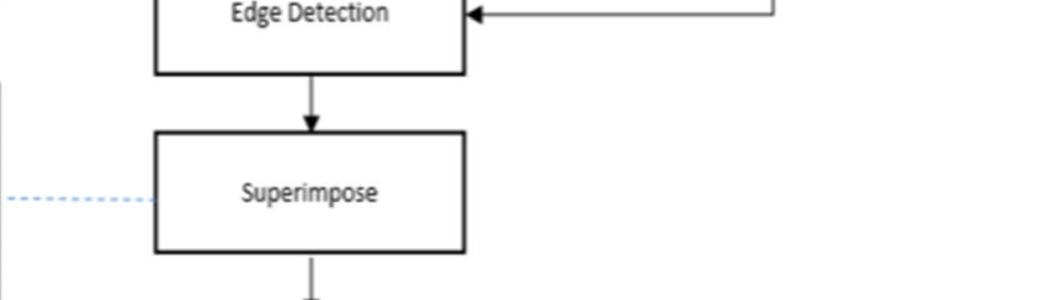
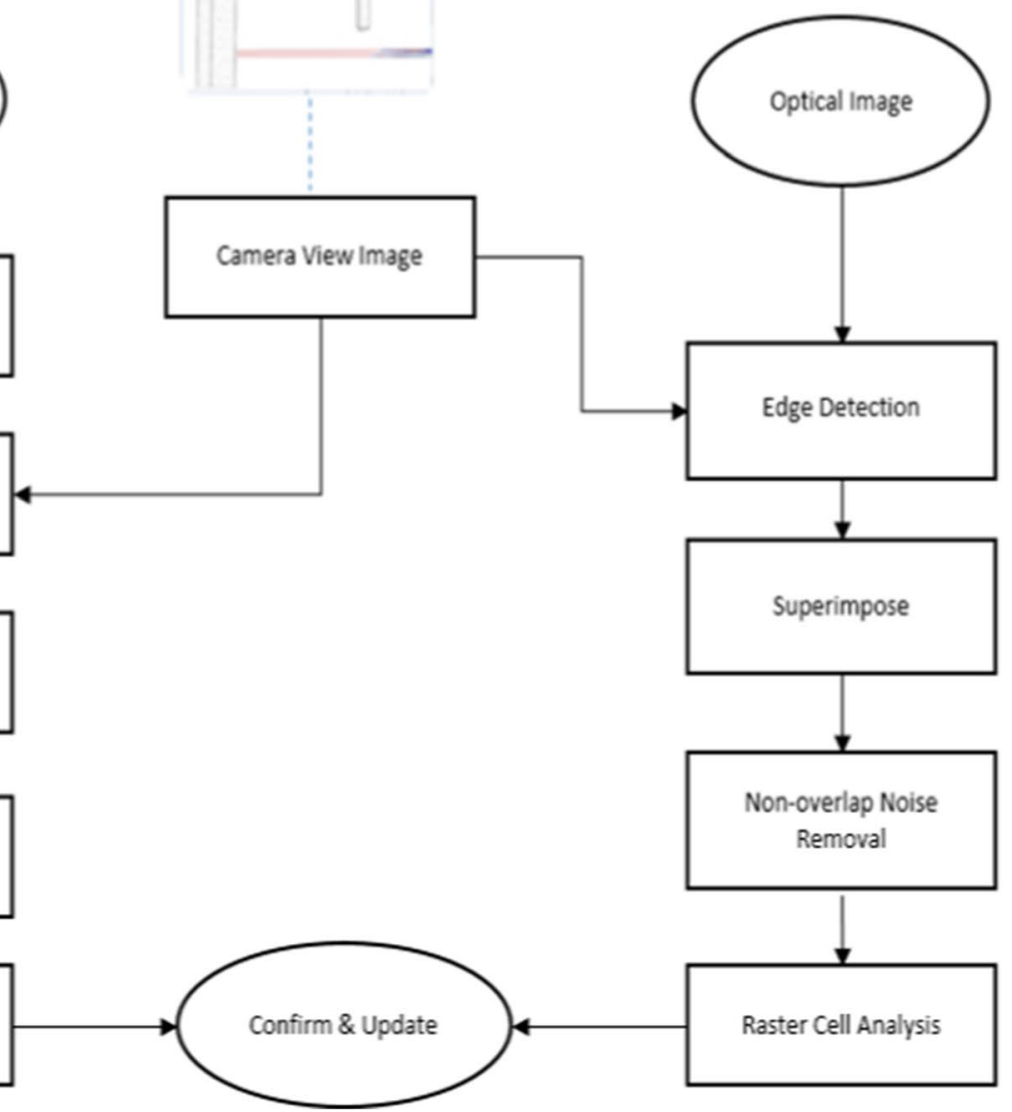

Fig. 10 Image processing method 
Fig. 11 Cell-by-cell encoding of raster cell

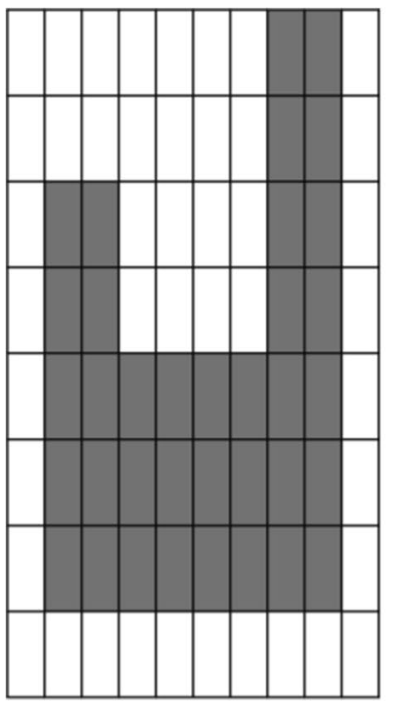

pictures and camera view image. After that, the raster cell method is applied to recognize the newly constructed components. The combination of the results from both thermal and optical image processing will lead to more accurate results for identification of components.

\section{Raster cell analysis}

Raster cell analysis is utilized to identify the percentage of matching of two images. Simply, a raster comprises a matrix of cells or pixels composed into rows and columns where each cell possesses a state representing information. In our case, state of a cell represents the existence situation of the concrete components. The images are rasterized with proper cell size for further processing. The cell size, or spatial resolution, of the raster depends on the level of details (of features). The cell must be sufficiently small to show the required detail. However, smaller cells are not often better due to the greater storage space, that often results in longer processing time.

Two states are considered for each cell: occupied and free. For instance, a cell can be defined as free when there are no points in it, which means that part does not exist. When it is not possible to make statement or few points are detected in the cell, it can be marked as potentially exists.

For encoding raster data from scratch, Cell-by-cell raster encoding method is utilized (Fig. 11), which is also referred as Exhaustive Enumeration [49]. This technique encodes a raster by making records for every cell magnitude by row and column. This strategy could be considered as an extensive spreadsheet wherein every cell of the spreadsheet demonstrates a pixel in the raster picture. By doing so, overlapped part can be identified between two images and existing components can be confirmed if the overlapped percentage exceeds certain threshold.

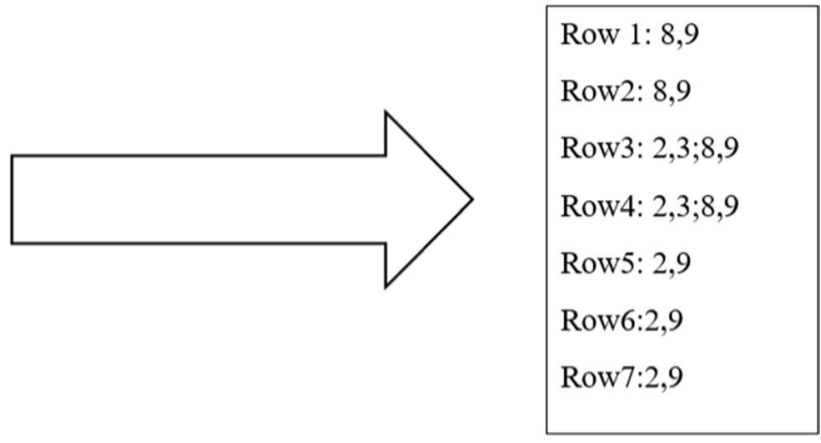

Based on the experimental assessment, the raster cell size of $1.5 \mathrm{~cm}$ has been considered. To avoid a hard threshold and to regard the uncertainty of the points, a percentage of $70 \%$ for "occupied" cells has been selected.

\section{BIM model updating}

Once the image processing step is finished, the results are interpreted by the plug-in in the form binary variables associated to completion (or absence) of respective building elements. These variables correspond to the schedule in the form of as-built schedule and thus 4D model is updated. However, if any deviations are present in the as-planned and as-built model, these will not be incorporated in the updated model but may result in reporting absence of the as planned element. When the newly constructed element is confirmed by the raster cell method, the date is updated on the elements' description in the 4D BIM model.

\section{Case studies}

A construction site, located in Suzhou, China, was chosen to investigate the proposed method (Fig. 12). This site is part of the south campus of Xian Jiaotong-Liverpool University which is designed for educational purposes. Suzhou is a city located in southeastern Jiangsu Province of East China with a four-season humid subtropical climate with hot, humid summers and cool, cloudy, damp winters. An IR-camera, NEC TH7102, was used to take pictures on site. The camera had a resolution of $320 \times 240$ with 76,800 pixels. The thermal sensitivity of the camera was less than $0.07{ }^{\circ} \mathrm{C}$ with the accuracy of $\pm 2{ }^{\circ} \mathrm{C}$. Utilizing a data cable, captured images were saved to the server in the JPEG image format for further processing. The time of image capturing was used 
Fig. 12 A partial BIM model of the construction site

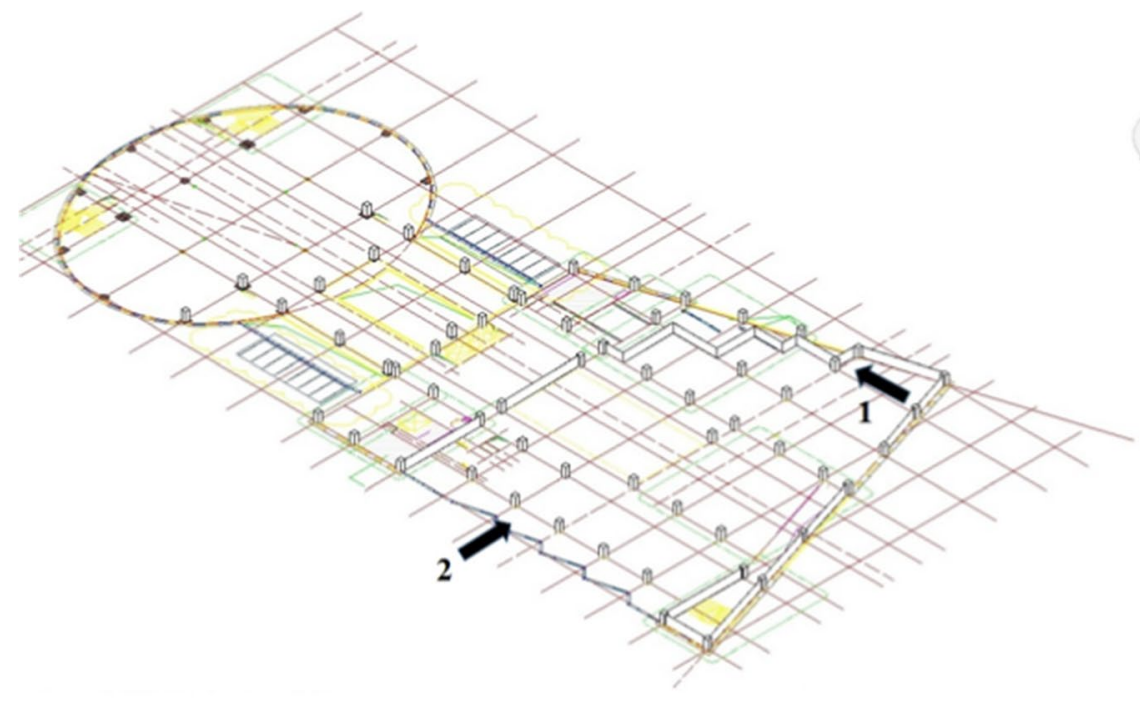

as the file name. For instance, when the image was captured at 14:23:29 on October, 24, 2019, the file name of thermal and optical images would be "T2019101124142329.jpg" and “O2019101124142329.jpg”, respectively. This information was used to identify the location data when connected to the location system mentioned previously. The coordinates of the camera were extracted from the tracking data recorded. It should be noted that a time boundary of $5 \mathrm{~s}$ is considered for each image and its correspondence location. This boundary reduced the error of mismatching images and positions. The orientation of the camera was added to the image data manually. A more accurate method, such as using a total station, could be applied in the future to improve the accuracy. These location data were utilized to extract the camera view image for the corresponding position in the 3D BIM model. Two test areas were selected to conduct the case studies, as shown in Fig. 12. Zone 1 was a typical area with two columns and a wall in between. Zone 2 was an area with noisy environment where scaffoldings are around the columns.

\section{Case study I - zone 1}

The optical and thermal images are depicted in Fig. 13(a) and (b), while Fig. 13(c) presents the camera-view image extracted from the BIM model based on coordinates and orientation of the IR-camera. Matlab R2010 is used for developing the image processing method. The applied edge detection on the camera-view image is depicted in Fig. 13(d).

An initial noise removal was implemented on the thermal image to remove the orange areas, as shown in Fig. 13(e). The superimposed image in Fig. 13(f) shows the overlapping of thermal and camera-view images. Next, raster cell method was implemented on the superimpose image and the output of both thermal and optical image processing are summarized in Table 1. From the thermal image assessments, part 2 has a rate of $97 \%$ while part 1 has the minimum confirmed raster cells by $79 \%$ as it is occupied by occlusions. Parts 3 and 4 have the confirmed raster cells by $90 \%$ and $82 \%$, respectively. It is clear that both images do not fully cover each other which can be explained by the slight differences of coordinates between real and estimated position due to accuracy. However, the percentage of objects confirmation for all parts has a successful range. The optical image results are almost same as the thermal image ones, except for part 3 where shadow influences the optical images and consequently poor result was achieved.

\section{Case study II - zone 2}

Figure 14(a) and (b) show the thermal image and initial noise removal image, respectively. The camera-view image extracted from the BIM model based on the related position and orientation is shown in Fig. 14(c). The result of edge detection is illustrated in Fig. 14(d). Figures 14(e) and (f) show the superimpose and the final noise removal stages.

Since the depth of two columns in the back side are the same, the camera-view image shows three columns in this position. However, only two columns are distinguished from both thermal and optical image assessment. The depth of camera view image is another factor which is needed to investigate further in our future research. The left column has a raster confirmation of $57 \%$ and $30 \%$ for thermal and optical images, respectively. The right column Percentage confirmation shows a wide difference between thermal and optical images by $80 \%$ for thermal and $10 \%$ for optical image. From the output of Table 2, it is evident that thermal image-based technique has the potential to identify new constructed components even in a noisy environment. 


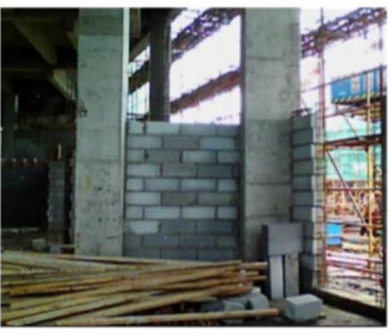

(a) Optical Image

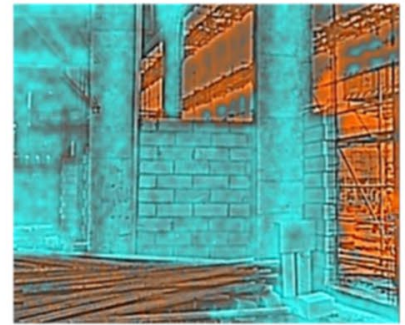

(b) Thermal Image

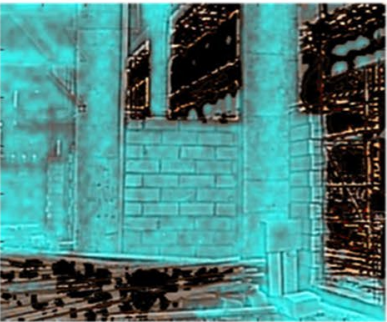

(e) Initial Noise Removal

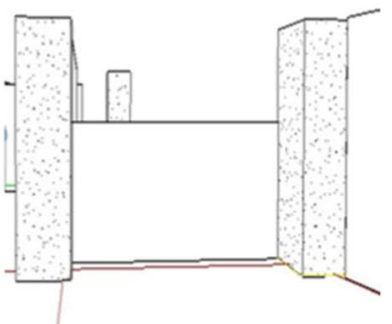

(c) Camera View Image in BIM

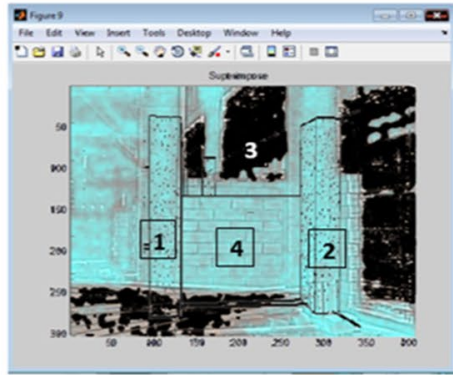

(f) Superimposed Image and final Noise Removal

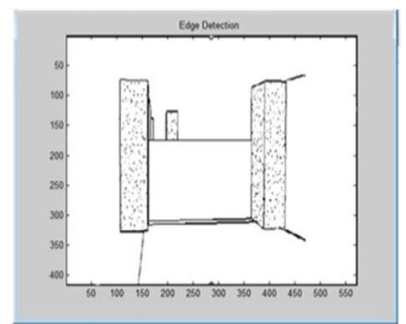

(d) Edge Detection Result from Camera View Image

Fig. 13 Case study for zone 1

Table 1 Percentage of confirmed raster cell per object

\begin{tabular}{lll}
\hline Part number & $\begin{array}{l}\text { Percentage confirmation } \\
\text { by thermal images }(\%)\end{array}$ & $\begin{array}{l}\text { Percentage confirma- } \\
\text { tion by optical images } \\
(\%)\end{array}$ \\
\hline 1 & 79 & 79 \\
2 & 97 & 96 \\
3 & 90 & 60 \\
4 & 82 & 80 \\
\hline
\end{tabular}

\section{Case study III}

In the previous two case studies, Rainbow filter was used to take thermal images. However, elements of the building built several months ago would not show significant temperature difference from the environment. In that case, Rainbow filter which only focuses on surface temperature may not be suitable or detecting existing elements. Therefore, other filters available in the IR-camera were investigated to further demonstrate the feasibility of applying the proposed method. For example, Humidity filter can be used to capture images showing the humidity of objects. A third case study was carried out by using the combined information captured using both Rainbow and Humidity filters in the IR-camera.

Figures 15(a), (b) and (c) illustrate the optical, thermal and humidity images taken for the concrete frame structure.
The same image processing method introduced before was implemented in this case study to identify existing building elements. Figure 15(d) illustrates the results based on the combination of optical, thermal and humidity images. Fifteen parts of the building were identified manually based on the structure in the raster cell plot. The grey areas represent the confirmed raster cells extracted from infrared images. Table 3 outlines the results for infrared and optical images. From the infrared image assessments, Part 13 has a rate of $95 \%$ of confirmed raster cell, while part 11 has not any confirmed raster cells as it is still under construction. Parts 14 and 15 can be identified by $66 \%$ and $72 \%$, respectively. Parts 3,4 and 5 could be detected easily from the humidity image as there are not covered by formworks. Parts 6, 7, 8 and 9 have few confirm raster cells and Part 10 is confirmed by a high percentage.

However, the results extracted from optical image are significantly less accurate than the combination of infrared images. For instance, part 13 , achieved $12 \%$ confirmed cells which is $83 \%$ less than the output of infrared technique. The optical image could achieve better result only for parts 5 and 2 by $6 \%$ and $5 \%$ improvement.

To sum up, in the first case study, all columns and walls could be identified by the use of thermal image. However, the slight differences of coordinates between real and estimated position, may result in not fully cover images in superimpose image that leads to lower confirmation in 


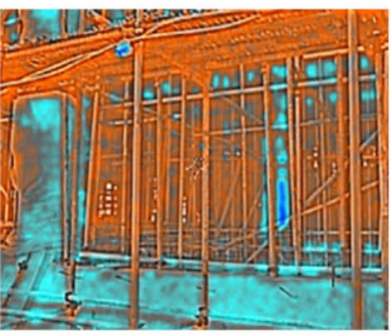

(a) Thermal Image

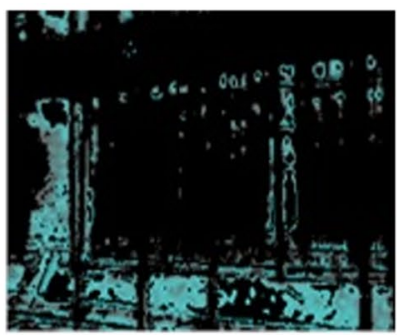

(b) Initial Noise Removal

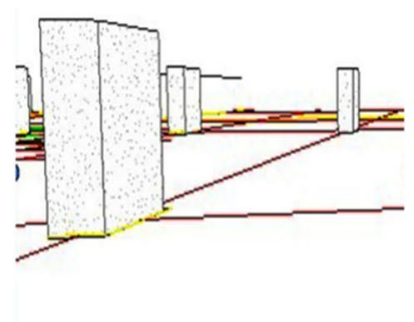

(c) Camera View Image in BIM

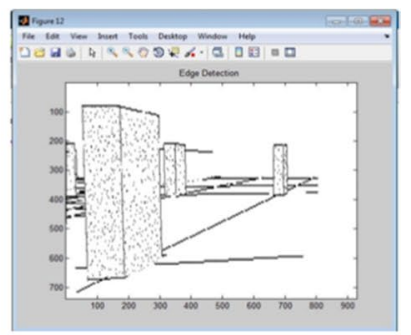

(d) Edge Detection Result from Camera View Image

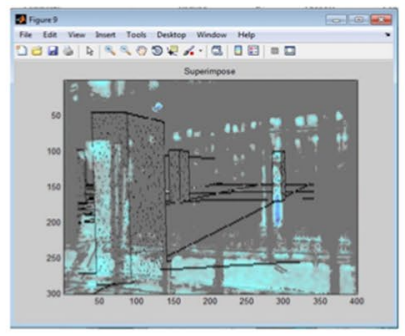

(e) Superimposed Image

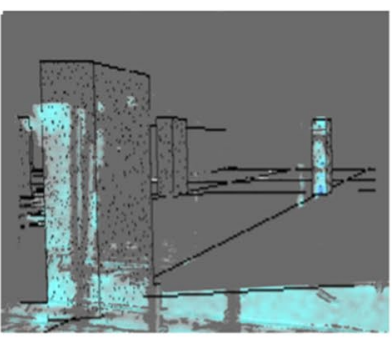

(f) final Noise Removal

Fig. 14 Case study for zone 2 in a noisy environment

Table 2 Percentage of confirmed raster cell per object

\begin{tabular}{lll}
\hline Part & $\begin{array}{l}\text { Percentage confirma- } \\
\text { tion by thermal images } \\
(\%)\end{array}$ & $\begin{array}{l}\text { Percentage confirma- } \\
\text { tion by optical images } \\
(\%)\end{array}$ \\
\hline Left Column & 57 & 30 \\
Right Column & 80 & 10 \\
Left behind column & 0 & 0 \\
\hline
\end{tabular}

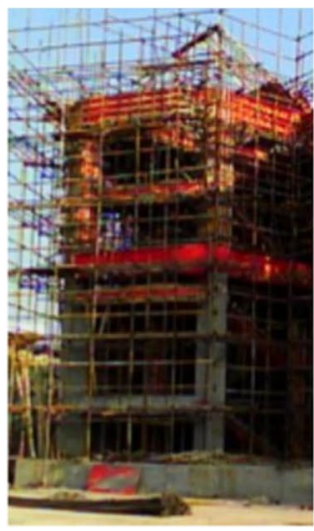

(a) Optical image

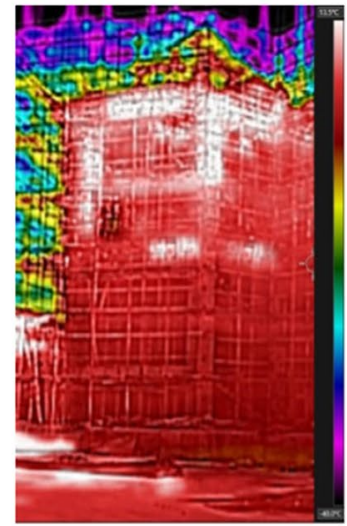

(b) Thermal image

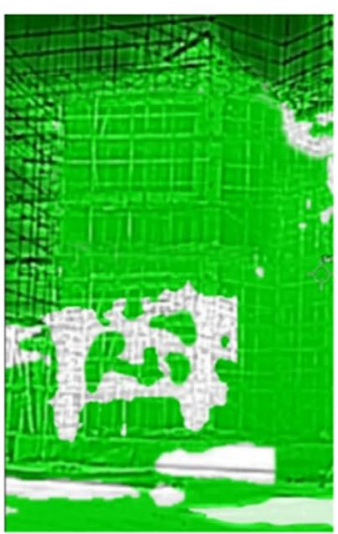

(c) Humidity image

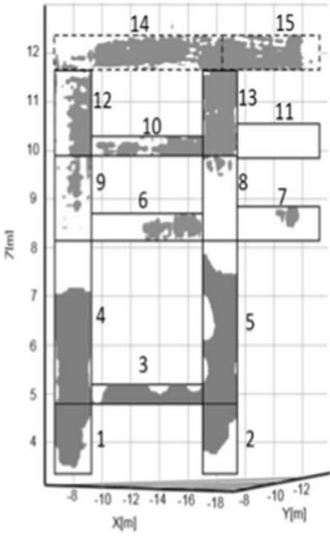

(d) Raster cells on elements surface

Fig. 15 Image processing for optical, thermal and humidity images [47] 
Table 3 Percentage of confirmed raster cell per object

\begin{tabular}{llllll}
\hline Part number & $\begin{array}{l}\text { Existing elements con- } \\
\text { firmed by infrared image } \\
(\%)\end{array}$ & $\begin{array}{l}\text { Existing elements con- } \\
\text { firmed by optical image } \\
(\%)\end{array}$ & $\begin{array}{l}\text { Part number } \\
\text { Non-existing element con- }\end{array}$ & $\begin{array}{l}\text { Non-existing element } \\
\text { confirmed by optical } \\
\text { image } \\
(\%)\end{array}$ \\
\hline 13 & 95 & 12 & 15 & 72 & 40 \\
3 & 79 & 15 & 14 & 06 \\
5 & 75 & 81 & 11 & 0 \\
10 & 71 & 5 & & \\
4 & 68 & 35 & & \\
1 & 67 & 23 & & \\
2 & 56 & 61 & & \\
12 & 55 & 3 & & \\
6 & 24 & 10 & & & \\
9 & 20 & 3 & & & \\
7 & 13 & 18 & & \\
8 & 8 & 0 & & & \\
\hline
\end{tabular}

For the third case study, the percentage average of existing components which confirmed by raster cell are $52.5 \%$ and $22.16 \%$ for infrared and optical images, respectively.

For components with the surface temperature adhere closely to the environment temperature, it is possible to use other filters in IR-Camera such as humidity filter. This filter can be implemented for old constructed parts or parts that stay in the shadow area. It can be concluded that image processing only on the optical photo, cannot identify all the building elements due to the low quality of image, poor lighting conditions and messy environment. However, the combination of optical, thermal and humidity images resulted in a high range of object detections that their effectiveness still needs further investigations.

\section{Conclusion and future works}

This paper presents an innovative approach to monitor construction progress projects using infrared camera and thermal image analysis. In the proposed approach, images can be of low quality or taken in a noisy environment. Characterized by concrete surface temperature, thermal image filter, colour-based noise removal, and the location calculation, image processing played an essential role in providing the necessary information for 4D BIM model updating. Thermal images offer more data than traditional digital photos. Temperature and humidity differences are the main parameters that are utilized to improve the quality of images for image processing. To identify the orientation and location of taken photos, a Zigbee wireless sensor network is utilized.
The main contribution of this study is that the proposed methodology succeeded in automating almost the entire process of 4D BIM updating using image processing. This methodology included site images acquisition, image analysis for progress identification, and 4D BIM model development. To the best of the author's knowledge, this study is one of the first comprehensive efforts to use IR-Camera for progress identification of construction sites.

Several case studies have been done and the results showed that to identify and monitor the progress of the constructed elements through image analysis and consequently to update the project schedule automatically, infrared based images could provide more accurate results than the traditional images (i.e. the average minimum and maximum improvement of $8.25 \%$ and $48.5 \%$ related to case studies I and II, respectively). However, all existing elements could not be verified ambiguously with collected data.

Future studies are required to further analysis of different filters of IR-Camera to evaluate the potential of concrete properties for progress monitoring. Iron filter is another embedded filter in IR-Camera with a high capability of covering steel components for progress monitoring purposes that requires further investigation.

Moreover, there are some other filters that can be applied on thermal images such as Iron, Lava and so on. Numerous empirical experiments showed that humidity and temperature filters are adequate to gain reasonable results in image processing.

\section{Declarations}

Conflict of interest On behalf of all authors, the corresponding author states that there is no conflict of interest. 


\section{References}

1. Zou H, Charlie Q, Xue L (2015) The impact of building control on urban planning and building management in Hong Kong. Building resilient cities in China: The nexus between planning and science. Springer 2015:375-389

2. Hannon J (2007) "The National Highway Cooperative Research Program (NHCRP) Synthesis 372: Emerging Technologies for Construction Delivery, A Synthesis of highway Practice In Transportation Research Record”. J Transport 50-57

3. Bosche F (2010) Automated recognition of 3D CAD model objects in laser scans and calculation of as-built dimensions for dimensional compliance control in construction. Adv Eng Inf 24(1):107-118

4. Bosche F, Hass C, Akinci B (2009) Automated recognition of 3D CAD objects in site laser scan for project 3D status visualization and performance control. J Comput Civ Eng 23(6):391-404

5. Hongjo K, Kinam K, Sungjae P, Jihoon K, and Hyoungkwan K (2014) "An Interactive Progress Monitoring System using Image Processing in Mobile Computing Environment." 2014 Proceedings of the 31stInternational Association for Automation and Robotics in Construction (ISARC), Sydney, Australia, 309-312

6. Zhang X, Bakis N, Lukins T, Ibrahim YM, Wu S, Kagioglou M, Aouad G, Kaka AP, Trucco E (2009) Automating progress measurement of construction projects. Autom Constr 18(3):294-301

7. Dai F, Rashidi A, Brilakis I, Vela P (2013) Comparison of imagebased and time-of-flight-based technologies for three-demensional reconstruction of infrastructure. J Constr Eng Manage 139(1):69-79

8. Omari MK, Lee J, Faqeerzada MA, Joshi R, Park E, Cho BK (2020) Digital image-based plant phenotyping: a review. Korean J Agric Sci 47(1):119-130

9. Gledson B, Greenwood D (2016) Surveying the extent and use of 4D BIM in the UK. J Inf Technol Constr 21:57-71

10. Navon R (2006) Research in automated measurement of project performance indicators. Autom Constr 16(2):176-188

11. Eastman C, Teichholz P, Sacks R, Liston K (2011) BIM Handbook: a guid to building information modeling for owners managers, designers, engineers and contractors. Hoboken: Wiley

12. Heigermoser D, de Soto BG, Abbott ELS, Chua DKH (2019) BIM-based Last Planner System tool for improving construction project management. Autom Constr 104(1):246-254

13. Su X, Cai H (2018) A graphical planning method for workspaceaware, four-dimensional modeling to assist effective construction planning. ITcon 23:340-353

14. Golparvar-Fard M, Pena-Mora F, Alboleda C, Lee S (2009) Visualization of construction progress monitoring with 4D simulation model overlaid on time-lapsed photographs. J Comput Civ Eng 23(6):391-404

15. Ibrahim YM, Lukins TC, Zhang X, Trucco E, Kaka AP (2009) Towards automated progress assessment of workpackage components in construction projects using computer vision. Adv Eng Inf 23(1):93-103

16. Lukins T, and Trucco E (2007) "Towards automatted visual assessment of progress in construction projects." Proceedings of the British Machine Vision Conference 2007, University of Warwick, UK, 18.1-18.10

17. Podbreznik P and Rebolj D (2007) "Real-time activity tracking system- The development process." 24th W78 Conf.: Bringing ITC Knowledge to Work, Maribor

18. Roberts D, Golparvar-Fard M (2019) End-to-end vision-based detection, tracking and activity analysis of earthmoving equipment filmed at ground level. Autom Constr 105:102811

19. Golparvar-Fard M, Pena-Mora F, Savarese S (2011) Integrated sequential as-built and as-planned representation with D4AR tools in support of decision-making tasks in the AEC/FM industry. J Constr Eng Manage 137(12):1099-1116

20. Changyoon K, Byoungil K, Hyoungkwan K (2013) 4D CAD model updating using image processing-based construction progress monitoring. Autom Constr 35:44-52

21. Shanbari HA, Blinn NM, Issa RR (2016) Laser scanning technology and BIM in construction management education. J Inf Technol Constr (ITcon) 21(14):204-217

22. Akinci B, Boukamp F, Gordon C, Huber D, Lyons C, Park K (2006) A formalism for utilization of sensor systems and integrated project models for active construction quality control. Autom Constr 15(2):124-138

23. Gordon C, Boukamp F, Huber D, Latimer E, Park K, and Akinci B (2003) "Combining reality capture technologies for construction defect detection: A case study." EIA9: E-Activities and Intelligent Support in Design and the Built Environment, 9th EuropIA International Conference, Istanbul

24. Park H, Lee H, Adeli H, Lee I (2007) A new approach for health monitoring of structures: terrestrial laser scanning. Comput Aided Civ Infrastruct Eng 22(1):19-30

25. Puri N, Turkan Y (2020) Bridge construction progress monitoring using lidar and 4D design models. Autom Constr 109:102961

26. Lu R, Brilakis I, Middleton CR (2019) Detection of structural components in point clouds of existing RC bridges. ComputAided Civ Infrastr Eng 34(3):191-212

27. Yang L, Cheng JC, Wang Q (2020) Semi-automated generation of parametric BIM for steel structures based on terrestrial laser scanning data. Autom Constr 112:103037

28. Turkan Y, Bosche F, Haas C, Haas R (2012) Automated progress tracking using $4 \mathrm{D}$ schedule and $3 \mathrm{D}$ sensing technologies. Autom Constr 22:414-421

29. Pučko Z, Šuman N, Rebolj D (2018) Automated continuous construction progress monitoring using multiple workplace real time 3D scans. Adv Eng Inform 38:27-40

30. Kiziltas S, Akinci B, Ergen E, Tang P (2008) Technological assessment and process implications and field data capture technologies for construction and facility/infrastructure management. J Inf Technol Constr 13:134-154

31. Neto J, Arditi D, Evens M (2002) Using colors to detect structural components in digital pictures. Comp Aided Civ Infrastruct Eng 17(1):61-67

32. Zou J, Kim H (2007) Using HSV color based space for construction equipment idle time analysis. J Comput Civ Eng 21(4):238-246

33. Zhu Z, Brilakis I (2010) Concrete column recognition in images and videos. J Comput Civ Eng 24(6):478-487

34. Braun A, Tuttas S, Borrmann A, and Stilla U (2015) "Automated progress monitoring based on photogrammetric point clouds and precedence relationship graphs." The 32nd International Symposium on Automation and Robotics in Construction and Mining (ISARC 2015), Oulu

35. Asadi K, Ramshankar H, Noghabaei M, Han K (2019) Real-time image localization and registration with BIM using perspective alignment for indoor monitoring of construction. J Comput Civ Eng 33(5):04019031

36. Ocaña SM, Guerrero IC, Requena IG (2004) Thermographic survey of two rural buildings in Spain. Energy Build 36(6):515-523

37. Ham Y, Golparvar-Fard M (2013) An automated vision-based method for rapid 3D energy performance modeling of existing buildings using thermal and digital imagery. Adv Eng Inform 27(3):395-409

38. Wang C, Cho YK, Gai M (2012) As-is 3D thermal modeling for existing building envelopes using a hybrid LIDAR system. J Comput Civ Eng 27(6):645-656 
39. Lagüela S, Armesto J, Arias P, Herráez J (2012) Automation of thermographic 3D modelling through image fusion and image matching techniques. Autom Constr 27:24-31

40. Lagüela S, Díaz-Vilariño L, Martínez J, Armesto J (2013) Automatic thermographic and RGB texture of as-built BIM for energy rehabilitation purposes. Autom Constr 31:230-240

41. Dimitrov A, Golparvar-Fard M (2014) Vision-based material recognition for automated monitoring of construction progress and generating building information modeling from unordered site image collections. Adv Eng Inform 28(1):37-49

42. González-Aguilera D, Lagüela S, Rodríguez-Gonzálvez P, Hernández-López D (2013) Image-based thermographic modeling for assessing energy efficiency of buildings façades. Energy Build 65:29-36

43. González-Jorge H, Lagüela S, Krelling P, Armesto J, MartínezSánchez J (2012) Single image rectification of thermal images for geometric studies in façade inspections. Infrared Phys Technol 55(5):421-426

44. Bison P, Bortolin A, Cadelano G, Ferrarini G, Furlan K, \& Grinzato E (2012) Geometrical correction and photogrammetric approach in thermographic inspection of buildings. In 11th International Conference on Quantitative InfraRed Thermography

45. Lagüela S, Diaz-Vilarino L, Roca D, \& Armesto J (2014) Aerial oblique thermographic imagery for the generation of building $3 \mathrm{D}$ models to complement Geographic Information Systems. Proc. of QIRT'14

46. Golparvar-Fard M, Peña-Mora F and Savarese S (2015) "Automated Progress Monitoring Using Unordered Daily Construction Photographs and IFC-Based Building Information Models". J Comput Civ Eng 29(1)

47. Pazhoohesh M, and Zhang C (2015) "A practical localization system based on principal component analysis." The 2nd World Congress on Computer Applications and Information Systems, Hammamet, Tunisia, 2015

48. Pazhoohesh M, Zhang C (2015) Automated construction progress monitoring using thermal images and wireless sensor networks. G E N 101:01

49. Zeiler M (1999) "Modeling Our World: The ESRI Guide to Geodatabase Design" ESRI, Inc. 151-160 